\title{
Mareike Kleine. 2013. Informal governance in the European Union. How governments make international organizations work. (Ithaca: Cornell University Press)
}

\author{
Simon Hug
}

Published online: 11 October 2013

(C) Springer Science+Business Media New York 2013

In this short book Marieke Kleine offers a theory on how and when informal governance in international organizations in general and in the European Union (EU) specifically operates. Thus, the book makes a contribution to the burgeoning literature on informal rules and governance. The author does so by offering first her own theory, modestly (and misleadingly) called Liberal Regime Theory, and showing how formal and informal governance works in the European Union (chapters 1 and 2). In three subsequent chapters she then offers varied evidence for her explanation of when informal governance should occur by focusing on agenda setting by the European Commission, decision-making by the European Council and the European Parliament, and implementation of policies within the EU (chapters 3 through 5). Chapter 6 provides a detailed discussion of how informal governance is chosen, namely by allowing a neutral actor to adjudicate whether a claim for stepping outside the formal rules is justified. Chapter 7 then argues that the rotating European Council presidency serves this function as neutral adjudicator and the next chapter illustrates this by studying European Council decision-making in one specific directive. The book's conclusion summarizes the findings and discusses the implications for the study of international organizations generally and future work on informal governance. Thus, the book innovates at the theoretical level by offering another explanation for informal governance than, for instance, Stone's (2011), at the conceptual level by proposing a way to identify informal governance, and finally at the empirical level by studying the role informal governance plays in the European Union. While these innovations are of great value, especially regarding the theoretical contribution, they also highlight the difficulties of this topic, especially at the conceptual and empirical level, difficulties that the author can only partly surmount.

Kleine's theory starts from the assumption that international institutions almost always have to deal with situations in which the domestic consequences of agreements are difficult to foresee. Thus, the formal rules that are part and parcel of any international

S. Hug $(\bowtie)$

Geneva, Switzerland

e-mail: simon.hug@unige.ch 
institution might lead to outcomes, due to the political uncertainty at the time when they were adopted, that are damaging for one or more of the contracting parties. A contracting party in such a situation might not live up to its treaty obligations, triggering, according to the formal rules, some punishment. This imposes, however, high domestic costs, which might be avoided by attempting to accommodate in an informal manner the contracting party with domestic problems. Doing so will first of all benefit the profiting contracting party but at the same time also allow for a more efficient functioning of the institution, or to quote Kleine: "Informal institutional elements are effective by virtue of their efficiency-enhancing effect" (32). The difficulty of this possible subterfuge to informal governance is obviously that it creates incentives for all contracting parties to pretend to have considerable domestic problems in order to receive special treatment under informal rules. According to the theoretical argument proposed, international institutions deal with this incentive problem by conferring the power to assess whether such a claim is genuine or not to an adjudicatory body, like, as Kleine argues, the rotating Council presidency in the EU. This constitutes the liberal regime theory, a notion used by many other scholars for a much broader variant of regime theory.

Given this explanation, Kleine expects informal governance to be prevalent in areas with high uncertainty and it should not reflect, as it does in the explanation offered by Randall Stone (2011), the power of the member state asking for an exception. In this book it is argued that the common agricultural policy (CAP), through its considerable welfare provisions (for a very small sector in the EU and not in each and every single member country, one might add), is an area where uncertainty has been heavily reduced. Consequently, "[a]1l else being equal, political uncertainty and, therefore, the demand for the norm of discretion is consequently relatively lower in the presence of welfare provisions than where welfare provisions are absent. Informal governance will vary accordingly" (27). Thus, according to this argument formal governance should dominate in decisions related to the CAP, while informal governance should be more likely in the other policy areas.

With this theoretical setup and a claim where informal governance should be less likely, Kleine proceeds to assess whether her claims are vindicated in three areas, namely in areas of agenda setting, adoption of policies and implementation of these policies in the EU. As the author cogently argues, work on informal governance is challenged at the conceptual level by an important definitional problem. What exactly is informal governance and how can we detect it and, God forbid, measure it? Her answer and proposal is to consider the predicted equilibrium behavior and outcomes under formal rules (i.e., treaties, etc., in the EU) as a baseline and any deviation from this baseline as the consequence of informal governance. While this is an elegant way to proceed, it obviously is only practical if we can easily and unambiguously identify what the equilibrium behavior is. Kleine quite rightly refers in this context, for instance, to the various game-theoretic studies on legislative decision-making, etc. She notes as well, however, that different authors (and by the way also legal scholars) interpret the formal rules of decision-making differently (see, for instance, the debate related to the question on the European Commission's gate-keeping power reviewed in Crombez et al. (2006)). Thus, equilibrium predictions derived from interpretation of formal rules using various formal models can be quite at odds with each other. Similarly, most scholars who have contributed to this burgeoning formal literature would concede that at best we have some partial models (and thus equilibria) at hand, 
and going in the direction of more encompassing models (for instance, considering also the European Commission appointment process in the EU, see Crombez and Hix (2011)) often leads to substantially different predicted equilibrium behavior. Thus, contrary to what Kleine wants us to believe, her elegant method to define and identify informal governance is not as neat and clean-cut.

This might also explain why the author eschews at the empirical level a clear operationalization of the key notion of informal governance through all the chapters. Each of the three chapters dealing with agenda setting, decision-making and implementation in the EU ends with a discussion of a table indicating, for policy areas with high and low political uncertainty and a series of time periods, whether formal or informal governance occurred. The text offers, however, no clear indication what criteria Kleine used to arrive at this classification of periods and policy areas as being subject to formal or informal governance. In various parts this lack of precision is disappointing as the arguments presented would have easily allowed, with suitable control variables, for more systematic assessments. For instance, the following statement offers a precise claim allowing for such a systematic assessment: "Formal governance is therefore a practice where governments cast votes frequently and openly, while informal governance is a practice where governments collectively refrain from voting in order to accommodate a government in the minority. This should be reflected in qualitative and quantitative [European] Council voting data" (46). The chapter dealing with council voting, however, does not offer such a systematic assessment (and refrains as well from considering the rather nuanced findings of recent work on European Council voting, see for instance Høyland and Hansen (2014)). Regarding the European Parliament, similar systematic assessments might have been possible based on the following argument: "Members of the European Parliament have a strong incentive to bring deliberations out into the open to gain the electoral support of their constituencies and, more generally, to justify their existence. Formal governance can therefore be considered a practice by which the European Parliament avails itself of opportunities to have public debates" (46). Again, this interesting claim is hardly pursued and, when it is, does not consider the broader context of the European Parliament's structure and organization (see Proksch and Slapin 2012).

The final chapters then argue that the Council presidency in the EU operates as a neutral adjudicator when a country requests changes to accommodate domestic opposition. According to Kleine, this should also lead the Council presidency to keep items that it dislikes off the agenda and instead to pass them on to the next presidency, as the adjudicator should be neutral. She offers, then, what one might consider as a plausibility probe by studying the decision-making of the End of Life Vehicles Directive and quotes from the secondary literature. Again, a systematic study of this claim would have put the argument on much more solid footing.

The author herself concludes that ". . . this book does not pretend to be the final word on the topic of informal governance. I probably have only scratched the surface" (159). A longer book, dealing in a more systematic way with the theoretical claims at the empirical level (as suggested at various instances in the book) would have led without doubt to a more marked contribution to the literature on informal governance and the European Union. Proceeding like this would also have allowed to assess more in detail when alternative explanations, for instance Stone's (2011) power-based one, fail, especially as Stone deals with the EU by using the Economic and Monetary 
Union as a case in point. This policy, however, is quickly dismissed in this book. Thus, the book offers an interesting theoretical scratch of the surface of informal governance, but misses the opportunity to delve deeper at the empirical level to show that this scratch is superior to those provided by other theories.

\section{References}

Crombez, C., \& Hix, S. (2011). Treaty reform and the Commission's appointment and policy making role in the European Union. European Union Politics, 12(3), 291-314.

Crombez, C., Groseclose, T., \& Krehbiel, K. (2006). Gatekeeping. The Journal of Politics, 68(2), 322-334.

Høyland, B., \& Hansen, V. W. (2014). Issue-specific policy-positions and voting in the Council. European Union Politics. doi:10.1177/1465116513495970.

Proksch, S.-O., \& Slapin, J. B. (2012). Institutional foundations of legislative speech. American Journal of Political Science, 56(3), 520-537.

Stone, R. W. (2011). Controlling institutions. New York: Cambridge University Press. 